\title{
Patterns of health care utilization and cost before and after opioid overdose: findings from 10-year longitudinal health plan claims data
}

This article was published in the following Dove Press journal:

Substance Abuse and Rehabilitation

16 August 2017

Number of times this article has been viewed

\author{
Daniel D Maeng' \\ John J Han² \\ Michael H Fitzpatrick ${ }^{3}$ \\ Joseph A Boscarino' \\ 'Department of Epidemiology \\ and Health Services Research, \\ ${ }^{2}$ Department of Pain Medicine, \\ ${ }^{3}$ Department of Emergency Medicine, \\ Geisinger Health System, Danville, \\ PA, USA
}

Correspondence: Joseph A Boscarino Department of Epidemiology and Health Services Research, Geisinger Health System, 100 North Academy Avenue, MC 44-00 Danville, PA 17822, USA Tel +I 5702149622

Email jaboscarino@geisinger.edu
Objective: To describe the longitudinal pattern of health care utilization and cost of care before and after opioid overdose (OD) over a 10-year period using health plan claims data.

Methods: Patients who had experienced opioid ODs between April 2005 and March 2015 were identified from Geisinger Health System's electronic health records. Among these patients, a subgroup of patients who were Geisinger Health Plan (GHP) members at any point between January 2006 and December 2015 were also identified. From the corresponding GHP claims data, their all-cause health care utilization (inpatient admissions, emergency department [ED] visits, and physician office visits) and total medical costs, excluding prescription medication cost, were obtained. Per-member-per-month estimates for each month before and after the index date of opioid OD were calculated, adjusting for age, gender, plan type, year, and comorbidity via multivariate regression models.

Results: A total of 942 opioid OD patients with an average GHP enrollment period of 41.4 months were identified. ED visit rates rose rapidly starting around 19-24 months prior to the opioid OD date. Acute inpatient admission rates and total medical cost also rose rapidly starting around 12 months prior. After the OD date, the utilization rates and cost declined but tended to remain above those of the pre-OD period.

Conclusion: Opioid OD is preceded by sharp increases in utilization of acute care and cost well before the actual OD. These findings therefore suggest that early signals of OD may be detected from patterns of acute care utilization, particularly the ED visits.

Keywords: opioid, overdose, utilization, cost of care, electronic health records, claims data

\section{Introduction}

The prevalence of prescription opioid drug abuse has increased over the past decade. ${ }^{1-4}$ Opioid overdose (OD) and mortality due to OD have also increased during this period. ${ }^{1,5,6}$ The increased risk of opioid OD death appears to be associated with higher opioid doses. ${ }^{7-10}$ In addition, previous studies have demonstrated that use of opioids is associated with higher health care utilization and total cost of care. ${ }^{11,12}$ Although the precise reasons for such an association are unclear, misuse and abuse of opioids resulting in OD are likely to be a major contributing factor. Currently, due to the increase in the prevalence of prescription opioid misuse and wider use of illicit opioids, such as heroin, there is growing interest in opioid OD surveillance in health care settings. ${ }^{13}$

At the same time, there has been a lack of studies in the literature evaluating the effectiveness of long-term (>1 year) opioid use to treat chronic pain; ${ }^{10}$ consequently, the impact of long-term opioid use on health care utilization and cost of care is also unknown. In particular, to our knowledge, no study has ever examined the patterns 
of longitudinal health care utilization and total cost of care leading up to and following opioid OD over substantial periods. Data describing what precedes an opioid OD may provide insights into developing strategies that can potentially prevent future OD, while data describing what happens following opioid OD can help inform follow-up care strategies. To the extent that prevention of OD and post-OD care management have implications for better patient outcome as well as substantial cost-of-care savings, understanding longitudinal patterns surrounding opioid OD is valuable. More specifically, the goal of this study is to describe the patterns of care utilization and cost at the patient population level from the perspective of a large health care delivery system responsible for providing comprehensive care for such patients. As such, this study uses health plan claims data that include total care utilization and cost, not just those that are OD related.

This study focuses on patients who have overdosed on opioids to assess their patterns of health care utilization and costs incurred over periods covering several years before and after an index opioid OD event, using 10-year data of those patients who were health plan members and were admitted to the Geisinger Health System for an opioid OD. The Geisinger Health System includes Geisinger Clinic, a hospital/provider network with over 40 primary care clinics, a tertiary care teaching hospital, and 10 other hospitals, and an insurance provider, the Geisinger Health Plan (GHP). Geisinger Health System serves $>3$ million community residents throughout 45 counties in central, south-central, and northeastern Pennsylvania and is the largest health care system in this region. Each of the hospitals in the Geisinger System has an onsite emergency department (ED), resulting in a combined annual volume of $>250,000$ emergency visits per year. ${ }^{14} \mathrm{GHP}$ is a regional health plan that provides health insurance to over a half million members; approximately half of GHP's total membership is composed of Medicaid or Medicare Advantage members. Approximately $40 \%$ of the patients treated by Geisinger Clinic also have GHP coverage.

This study therefore builds upon the previous study by Boscarino et $\mathrm{al}^{14}$ by focusing on the subset of Geisinger Clinic's patients who also had GHP coverage at or around the same time. This study has been approved by Geisinger Health System's Institutional Review Board (IRB). Under Geisinger's IRB policy, patient consent is not required for biomedical research using limited data (i.e., only dates were included in the data set as protected health information), because such studies are considered minimum risk by the Geisinger IRB, given the study meets all other IRB requirements.

\section{Methods}

As described in the earlier study, ${ }^{14}$ the eligible population for this study included all patients who met the following criteria between April 1, 2005, and March 31, 2015: had an ICD-9 diagnosis code for opioid OD (defined as ICD-9 codes 965.00, 965.01, 965.02, 965.09 or ICD-9 'E' codes E850.0, E850.1, E850.2, E935.0, E935.1, E935.2) and had any inpatient, ED, or outpatient clinic visit during this time period. Patients included in this study were between 18 and 95 years old. Younger patients were excluded because they are likely to be subject to different clinical and social factors unique to the pediatric patient population. Since this was a service area investigation of OD cases, all opioid ODs were included in this study, including both prescription and nonprescription opioids, illicit opioids such as heroin, and synthetic opioids used in addiction treatment, such as methadone.

Geisinger's electronic health records were queried to identify the patients who met the abovementioned inclusion criteria. Then, the patient sample was further restricted by excluding those who did not have GHP coverage at any point between January 1, 2006, and December 31, 2016, using the available claims data. Earlier GHP claims data were not available for the purposes of this study. No minimum or maximum GHP enrollment length was specified to further restrict the sample. Given the objective of this study, patients who either had coverage lapse or did not maintain GHP coverage for the entire study period still contributed to the analysis based on their index OD dates. For instance, if a patient had an index OD date in June 2010 and had GHP coverage only during the calendar years 2009 and 2011, the available claims experiences contributed to describing her utilization and cost patterns 6-18 months prior to and 6-18 months after the index OD date. Moreover, patients who had deceased after OD were not excluded from the sample, because such patients were indistinguishable from the patients who had discontinued their GHP enrollment. As a sensitivity check, however, a separate analysis was conducted excluding those patients who had deceased within 1 year after the OD date. The prior study by Boscarino et $\mathrm{al}^{14}$ indicated $<10 \%$ of such patients in the sample.

To capture health care utilization, the following variables were considered: per-member-per-month (PMPM) all-cause rates of acute inpatient admissions, outpatient ED visits, primary care provider visits, and specialist visits. Cost of care was defined as total medical allowed amounts, which are the sum of the health plan's payments to all the health care providers and the members' total out-of-pocket expenses (i.e., deductibles, copays, and co-insurance) for all the care 
covered under the plan's medical benefit in a given month. Prescription drug costs were not considered because not all the patients in the sample had prescription drug coverage through GHP.

Because the patients were observed over multiple years across different health plan types (e.g., patients might have transitioned across Medicaid, commercial, and/or Medicare coverage over time), the utilization and cost data were influenced by various confounders. Therefore, a set of Poisson regression models was used to estimate the utilization variables, and a generalized linear model with log link and gamma distribution was used to estimate the cost of care, adjusting for the following covariates: age, gender, health plan type (Medicare, commercial, or Medicaid), calendar year indicators, and presence of the following comorbid conditions: chronic kidney disease, diabetes, asthma, congestive heart failure, chronic obstructive pulmonary disease, coronary artery disease, hypertension, cancer, and depression. Bootstrap standard errors were obtained with 100 replications to construct $95 \%$ confidence intervals. The bootstrap method was used because the utilization and cost data were aggregated estimates (to PMPM level), and therefore, the true distribution of these estimates is unknown. Bootstrapping addresses this problem by obtaining standard errors that are based on the empirical distribution of the data. ${ }^{15}$

\section{Results}

After applying the inclusion criteria as described earlier, 942 patients have been identified, representing 39,017 member-month observations during the study period. On average, this corresponds to 41.4 months of observation per member (standard deviation $=36.0$; median $=29$; interquartile range $=13-60$ ), as well as an average of 32.6 months of pre-OD observation (standard deviation $=30.0$; median $=22$; interquartile range $=9-50$ ) and an average of 24.6 months of post-OD observation ( standard deviation $=22.6$; median $=19$; interquartile range $=9-33$ ). Table 1 shows the descriptive statistics of the overall sample as well as selected comparisons between the pre-OD and post-OD observations. Table 1 indicates that after the index OD, the rates of all the health care utilization and the average total medical cost had increased significantly relative to the pre-OD periods. In addition, prevalence of certain chronic conditions, particularly depression, appears to have increased significantly after the index OD. Moreover, the proportion of patients who had enrolled in Medicaid also appears to have increased significantly after the

Table I Descriptive statistics

\begin{tabular}{|c|c|c|c|c|}
\hline Variables & Overall & Pre-OD & Post-OD & p-value* \\
\hline \# Unique members & 942 & 581 & 817 & \\
\hline \# Member-month observations & 39,017 & 18,948 & 20,069 & \\
\hline \multicolumn{5}{|l|}{ Demographic } \\
\hline Female & $60.9 \%$ & $59.8 \%$ & $61.9 \%$ & 0.465 \\
\hline Age, years & 54.2 & 56.5 & 52.0 & $<0.001$ \\
\hline \multicolumn{5}{|l|}{ Health plan type } \\
\hline Medicaid & $16.6 \%$ & $4.6 \%$ & $27.9 \%$ & $<0.001$ \\
\hline Medicare & $37.1 \%$ & $37.5 \%$ & $36.7 \%$ & 0.767 \\
\hline Commercial & $46.3 \%$ & $57.8 \%$ & $35.5 \%$ & $<0.001$ \\
\hline \multicolumn{5}{|l|}{ Cost and utilization (PMPM) } \\
\hline Mean count of acute inpatient admits & 0.048 & 0.035 & 0.060 & $<0.001$ \\
\hline Mean count of ED visits & 0.107 & 0.075 & 0.136 & $<0.001$ \\
\hline Mean count of PCP visits & 0.357 & 0.338 & 0.375 & 0.012 \\
\hline Mean count of specialist visits & 0.348 & 0.324 & 0.372 & 0.014 \\
\hline Mean total medical cost (US\$) & 1,450 & $\mathrm{I}, \mathrm{I} 64$ & 1,719 & $<0.001$ \\
\hline \multicolumn{5}{|l|}{ Comorbidity } \\
\hline Chronic kidney disease & $9.2 \%$ & $7.0 \%$ & $11.3 \%$ & 0.005 \\
\hline Diabetes & $22.5 \%$ & $22.0 \%$ & $22.9 \%$ & 0.71 \\
\hline Asthma & $16.2 \%$ & $10.6 \%$ & $21.4 \%$ & $<0.001$ \\
\hline Congestive heart failure & $8.1 \%$ & $6.6 \%$ & $9.5 \%$ & 0.032 \\
\hline Chronic obstructive pulmonary disease & $10.6 \%$ & $8.6 \%$ & $12.5 \%$ & 0.021 \\
\hline Coronary artery disease & $21.5 \%$ & $19.4 \%$ & $23.6 \%$ & 0.060 \\
\hline Hypertension & $44.7 \%$ & $44.2 \%$ & $45.2 \%$ & 0.712 \\
\hline Cancer & $10.2 \%$ & $9.5 \%$ & $10.9 \%$ & 0.365 \\
\hline Depression & $29.0 \%$ & $17.5 \%$ & $39.9 \%$ & $<0.001$ \\
\hline
\end{tabular}

Note: *Results from clustered two-sample $t$-tests comparing the pre-OD and post-OD statistics, allowing for correlations within the same patient over time. Abbreviations: OD, overdose; PMPM, per-member-per-month; ED, emergency department; PCP, primary care provider. 
index OD, while the proportion of patients who had enrolled in commercial plans (i.e., employer-sponsored health insurance) had decreased by roughly the same magnitude as that of the increase in Medicaid.

Figure 1 shows the unadjusted longitudinal patterns of health care utilization and total medical cost over several years before and after the index OD. Not surprisingly, the highest utilization and cost occur during the first 6 months since the index OD. However, this is preceded by steady increases in acute care utilization, particularly ED visits, well before the index OD takes place. After the OD, the acute care utilization and cost decline but remain persistently higher than the pre-OD period average.
As noted earlier, the unadjusted estimates shown in Figure 1 are subject to various confounders. Figures 2 and 3 therefore show the regression-adjusted estimates, holding constant the patient gender (female), age (56-70 years), plan type (Medicaid), calendar year (2015), and comorbidity (has hypertension, diabetes, and depression). These covariate values have been chosen to approximate the average patient in our sample, as described in Table 1. Figures 2-4 therefore show the mean values as well as the corresponding bootstrap $95 \%$ confidence intervals. In all cases, the overall patterns shown by the regression-adjusted estimates are similar to those of the unadjusted estimates shown in Figure 1.
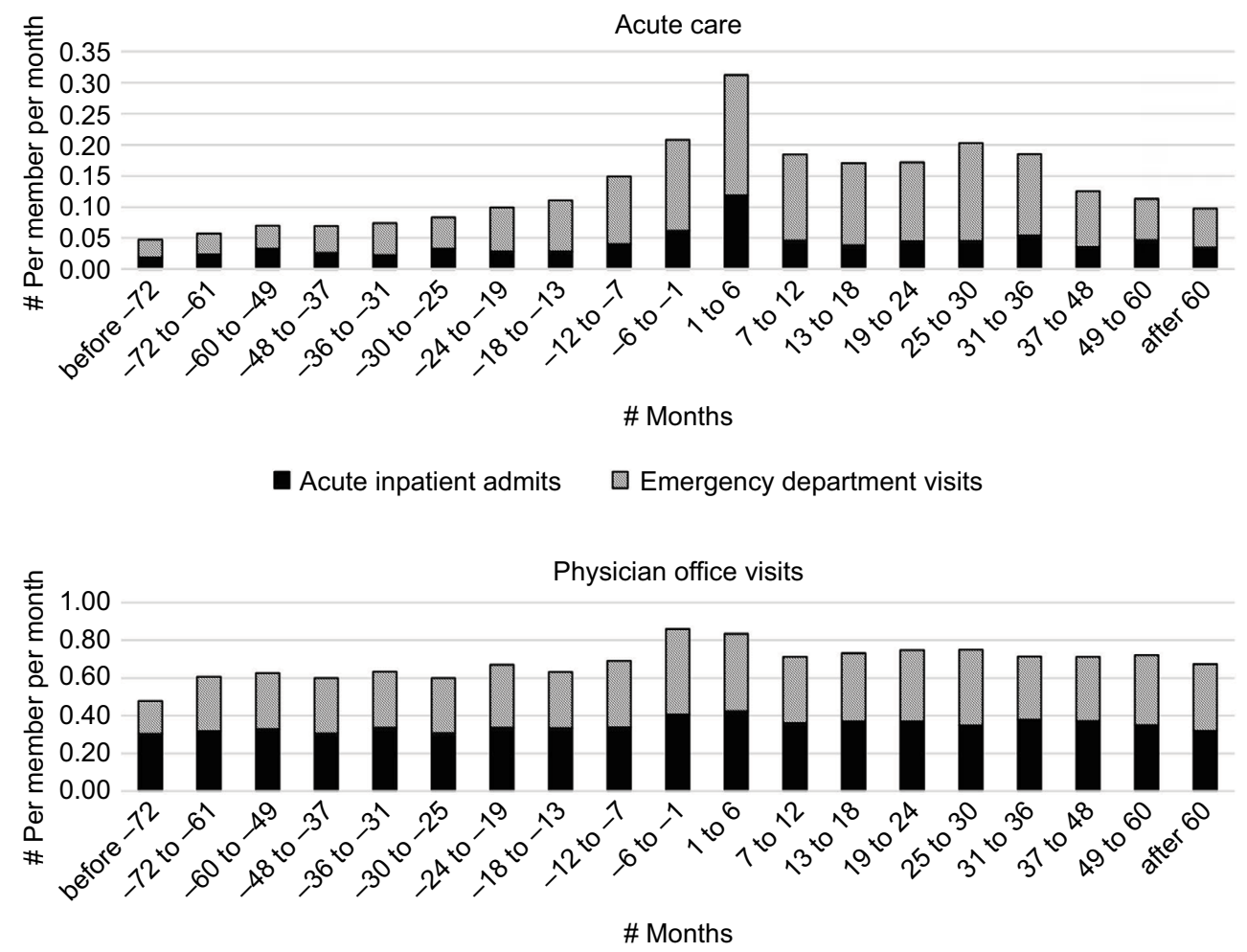

- Primary care physician $\square$ Specialist

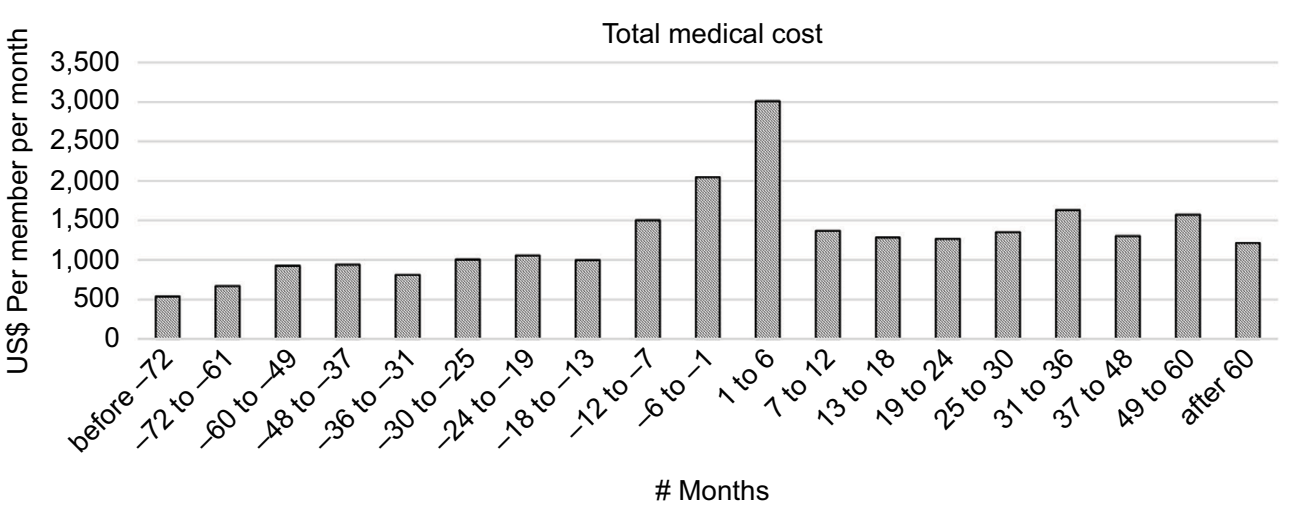

Figure I Unadjusted longitudinal health care utilization and cost patterns before and after opioid overdose. 

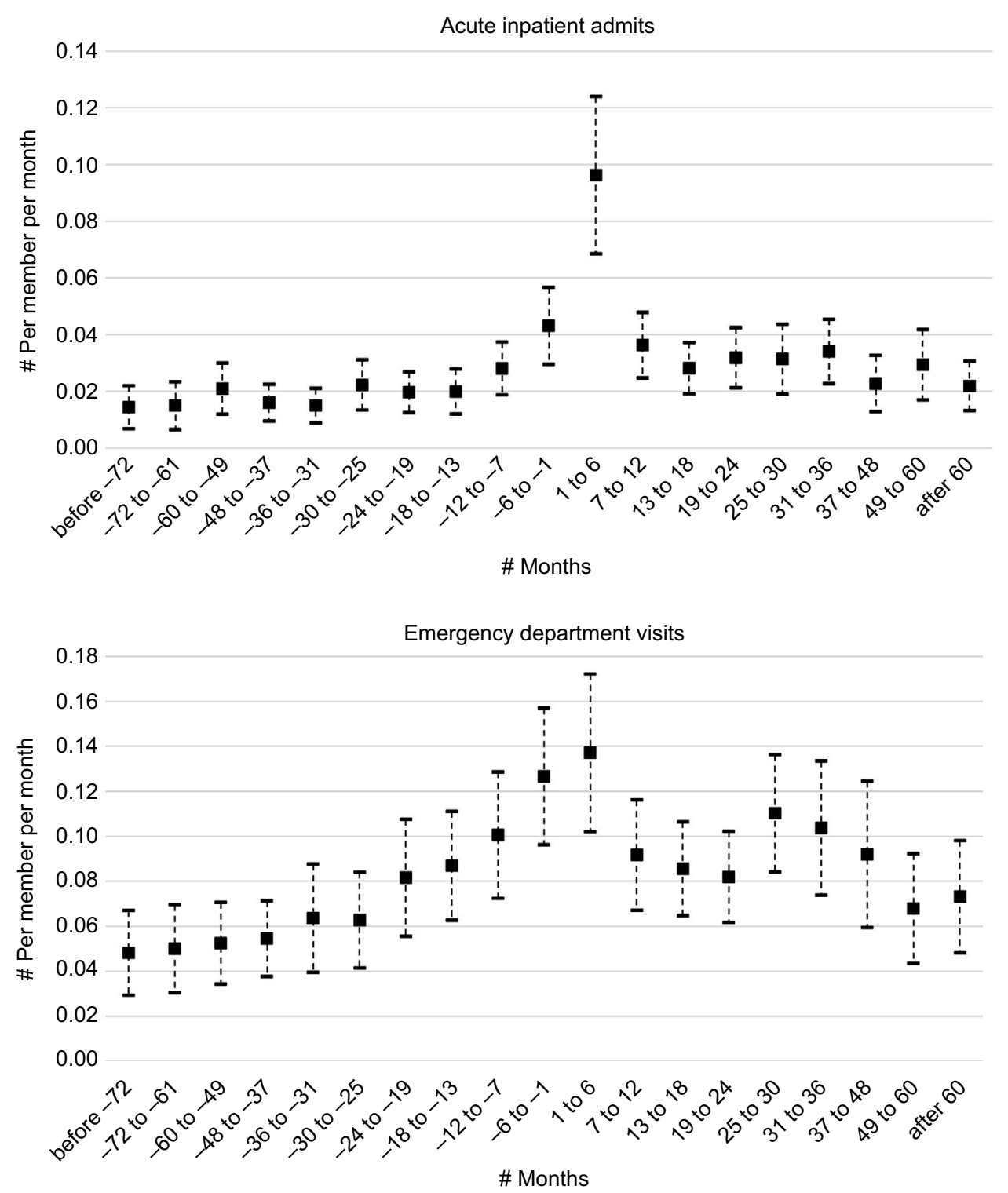

Figure 2 Regression-adjusted acute care utilization patterns before and after opioid overdose.

In particular, the regression-adjusted estimates in the ED visits (Figure 2) show a more pronounced pattern of a steady increase starting in the 19- to 24-month interval prior to the index OD. Then during the 6-month period immediately before the index OD date, the ED visit rate nearly doubles relative to the $25+$ months prior to the index OD date. Moreover, after the index OD, the ED visit rate steadily declines but then sharply increases again $\sim 2$ years after the index OD. The regression-adjusted estimates for the total medical cost (Figure 4) appear to follow the ED visit pattern shown in Figure 2.

As noted earlier, a separate set of regression analyses has been conducted excluding those patients who had deceased within 1 year after the OD date as a sensitivity check.
Approximately $7 \%$ of the patients in the sample (66 of 942) had died within 1 year of the OD date. The results of this sensitivity check (shown in the Supplementary materials) indicate that the main results are not sensitive to the exclusion of these deceased patients in the sample. In addition, 47 patients of the 942 in the sample had experienced additional opioid OD after the index OD date. Because they constituted $<5 \%$ of the sample, a separate sensitivity check for these patients was not carried out.

\section{Discussion}

As mentioned earlier, the goal of this study is to describe the patterns of care utilization and cost at the patient population level from the perspective of a large health care delivery 

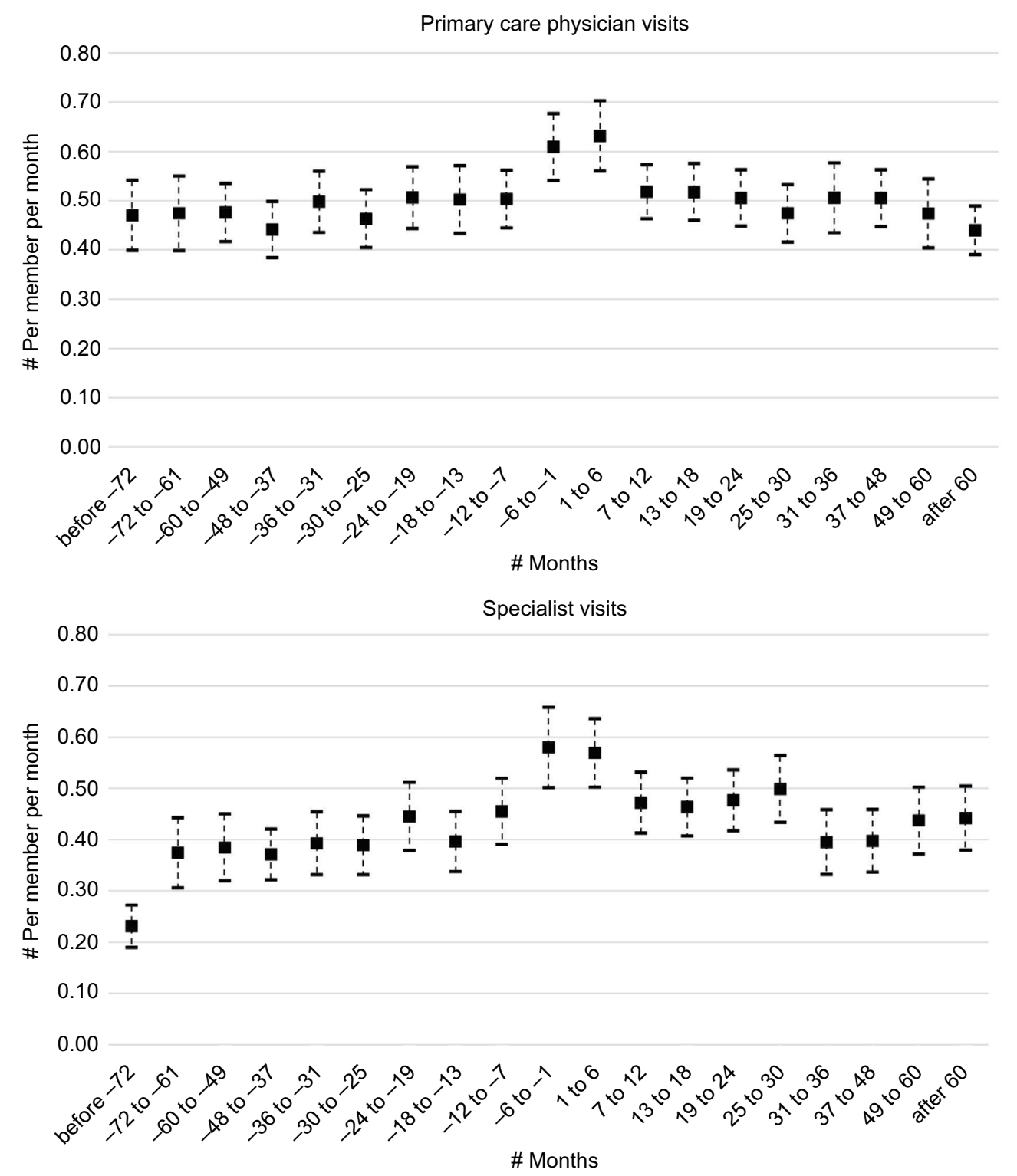

Figure 3 Regression-adjusted physician office visit patterns before and after opioid overdose.

system responsible for providing comprehensive care for such patients. As such, the study has focused on aggregated PMPM-level data, rather than on individual patients' experiences over time. The findings of this study suggest that there is likely to be a pattern of health care utilization among the opioid OD patients that correlates with future likelihood of opioid OD well in advance. The results reveal that there is a clear escalation of utilization of acute care, particularly the ED visits, as early as 2 years prior to the OD. If such a signal can be identified, it will provide ample time and opportunity for health care providers and other key stakeholders to intervene and avoid future OD. At the same time, there does not appear to be as strong patterns or signals evident through physician office visits. Moreover, as suggested by Figure 2,
OD patients who survive one OD may face a high likelihood of experiencing other future episodes that require additional ED visits, as shown by the second peak after $\sim 2$ years following the index OD. Unlike the previous OD, however, there does not appear to be a similar escalation preceding the second peak. This implies the importance of designing and implementing follow-up care after the initial OD discharge.

The results of this study also confirm that consequences of opioid OD extend beyond health outcomes. First, the high utilization of acute care and the corresponding high cost of care existing well before and after the opioid OD episode may indicate inefficient utilization or a lack of appropriate health care resources. Second, although not fully explored in this study, the increases in the prevalence of certain chronic conditions 


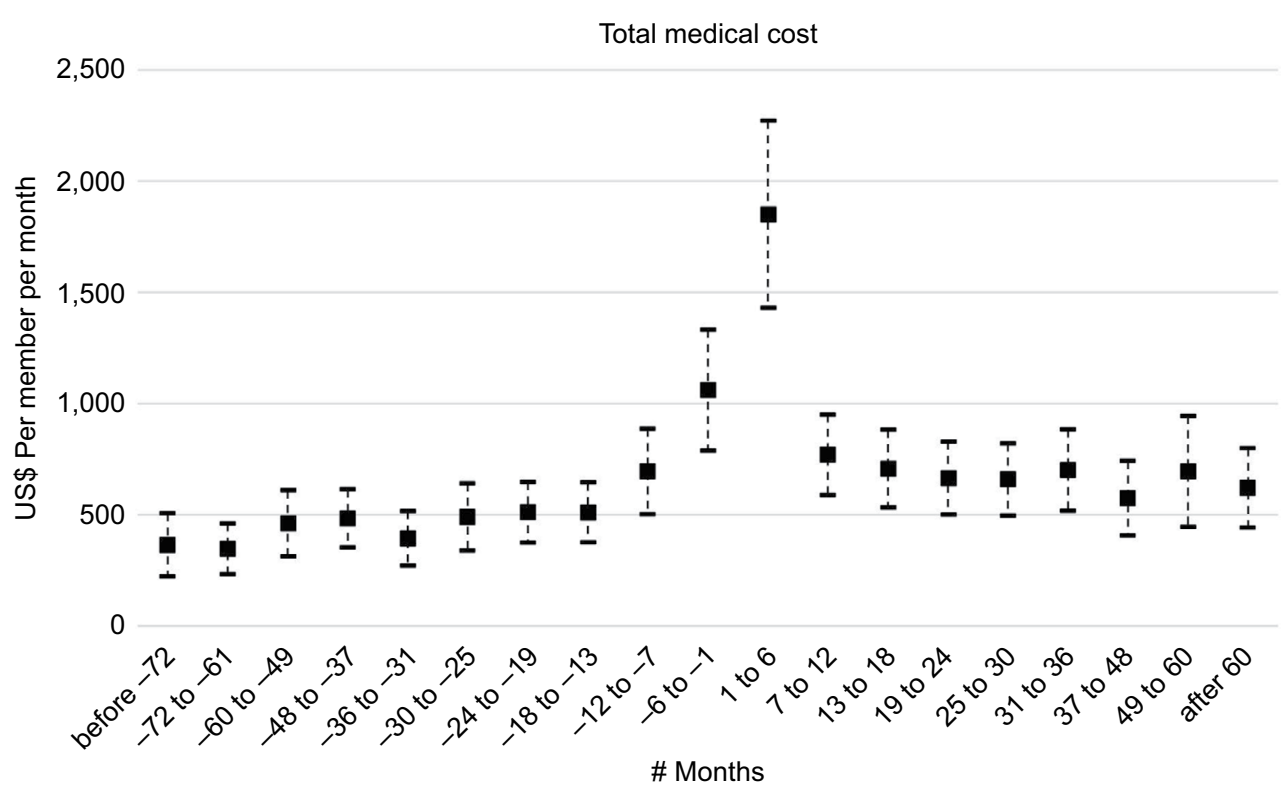

Figure 4 Regression-adjusted total medical cost before and after opioid overdose (in 2015 US dollars).

associated with the post-OD periods, such as seen for depression, and the increased proportion of patients with Medicaid are suggestive of the long-term negative impacts that the opioid OD seems to have on those patients who survive the first episode of OD. Alternatively, the apparent higher prevalence of chronic conditions after OD may also reflect previously undiagnosed health conditions that had been presented prior to OD.

The results of this study, however, also imply that there may be opportunities to address the causes and consequences of opioid OD. The fact that all the OD patients included in the sample have a health care provider within a single integrated health care delivery system and also have health insurance coverage implies the possibility that there may be resources within the health care system to address this problem. Thus, opportunities for OD prevention, including identification of at-risk populations, better health care system communications, improving access to naloxone in patient care settings, and follow-up care for substance use disorders may have a significant impact on the reduction of opioid ODs and adverse OD outcomes, such as death. ${ }^{12-14,16}$

This study is subject to several limitations. First, the data have been collected from patients within a single health care delivery system in Central Pennsylvania. Therefore, the results may not be generalizable to other health care systems in different geographical areas. Moreover, the data include only those patients who had GHP coverage during the study period; it is not clear whether and how having GHP coverage (either continuously throughout the study period or only partially) might have impacted the observed patterns in the data. Second, the study population has been limited to members of a single health plan; therefore, the utilization patterns and the cost of care may still be confounded by the plan's benefit structure, coverage limits, and care management efforts. As such, future studies may include claims data from other health plans to improve generalizability of the findings. Furthermore, future studies may also consider identifying patient subgroups within the opioid OD population, as this study has focused on the overall opioid OD population. There may be certain patient subgroups for whom the observed patterns are different from what is reported in this study. Also, due to the aggregated nature of the data used, this study lacks clinical information that may provide further insight on the results. Lastly, the study considered all-cause health care utilization and costs excluding prescription medications. Future studies may consider identifying and focusing specifically on opioid OD-related utilizations, particularly prescription medication use, to provide more detailed insights into the patterns of health care utilization surrounding opioid OD.

\section{Conclusion}

Opioid OD is preceded by sharp increases in utilization of acute care and cost well before the actual OD, suggesting that early signals of OD may be detected from patterns of acute care utilization, particularly the ED visits. Provision of follow-up care after OD is also important as the utilization of acute care remains high well after the initial OD. The findings from this study therefore imply that developing strategies to prevent future OD may be feasible and have crucial impli- 
cations for improving long-term patient health outcomes, reducing the cost of care, and lowering patient mortality.

\section{Acknowledgment}

Support for this study included research funding from Indivior, Inc., Richmond, VA, USA.

\section{Disclosure}

Dr Maeng conducted this study as a part of his employment with Geisinger Health System. All authors are current employees of Geisinger Health System. The authors report no other conflicts of interest in this work.

\section{References}

1. Manchikanti L, Fellows B, Ailinani H, Pampati V. Therapeutic use, abuse, and nonmedical use of opioids: a ten-year perspective. Pain Physician. 2010;13(5):401-435.

2. Von Korff M, Kolodny A, Deyo RA, Chou R. Long-term opioid therapy reconsidered. Ann Intern Med. 2011;155(5):325-328.

3. Kuehn BM. SAMHSA: pain medication abuse a common path to heroin: experts say this pattern likely driving heroin resurgence. JAMA. 2013;310(14):1433-1434.

4. Boscarino JA, Rukstalis M, Hoffman SN, et al. Risk factors for drug dependence among out-patients on opioid therapy in a large US healthcare system. Addiction. 2010;105(10):1776-1782.

5. Hasegawa K, Espinola JA, Brown DF, Camargo CA Jr. Trends in U.S. emergency department visits for opioid overdose, 1993-2010. Pain Med. 2014;15(10):1765-1770.
6. Rudd RA, Aleshire N, Zibbell JE, Gladden RM. Increases in drug and opioid overdose deaths - United States, 2000-2014. MMWR Morb Mortal Wkly Rep. 2016;64(50-51):1378-1382.

7. Bohnert AS, Valenstein M, Bair MJ, et al. Association between opioid prescribing patterns and opioid overdose-related deaths. JAMA. 2011;305(13):1315-1321.

8. Dunn KM, Saunders KW, Rutter CM, et al. Opioid prescriptions for chronic pain and overdose: a cohort study. Ann Intern Med. 2010;152(2):85-92.

9. Gomes T, Mamdani MM, Dhalla IA, Paterson JM, Juurlink DN. Opioid dose and drug-related mortality in patients with nonmalignant pain. Arch Intern Med. 2011;171(7):686-691.

10. Chou R, Turner JA, Devine EB, et al. The effectiveness and risks of long-term opioid therapy for chronic pain: a systematic review for a National Institutes of Health Pathways to Prevention Workshop. Ann Intern Med. 2015;162(4):276-286.

11. Kern DM, Zhou S, Chavoshi S, et al. Treatment patterns, healthcare utilization, and costs of chronic opioid treatment for non-cancer pain in the United States. Am J Manag Care. 2015;21(3):e222-e234.

12. Zedler B, Xie L, Wang L, et al. Development of a risk index for serious prescription opioid-induced respiratory depression or overdose in veterans' health administration patients. Pain Med. 2015;16(8): $1566-1579$.

13. Mueller SR, Walley AY, Calcaterra SL, Glanz JM, Binswanger IAA. Review of opioid overdose prevention and naloxone prescribing: implications for translating community programming into clinical practice. Subst Abuse. 2015;36(2):240-253.

14. Boscarino JA, Kirchner HL, Pitcavage JM, et al. Factors associated with opioid overdose: a 10-year retrospective study of patients in a large integrated health care system. Subst Abuse Rehabil. 2016;7:131-141.

15. Cameron AC, Trivedi PK. Microeconometrics Using Stata. College Station, TX: Stata Press; 2009.

16. Humphreys K. An overdose antidote goes mainstream. Health Aff. 2015;34(10):1624-1627. 


\section{Supplementary materials}

Table SI Full regression output for total cost and acute care

\begin{tabular}{|c|c|c|c|c|c|c|}
\hline \multirow[t]{2}{*}{ Covariate } & \multicolumn{2}{|c|}{$\begin{array}{l}\text { Total medical cost } \\
\text { (coefficient, SE) }\end{array}$} & \multicolumn{2}{|c|}{$\begin{array}{l}\text { Acute inpatient admission } \\
\text { (coefficient, SE) }\end{array}$} & \multicolumn{2}{|c|}{ ED visit (coefficient, SE) } \\
\hline & All & Exclude deceased & All & Exclude deceased & All & Exclude deceased \\
\hline \multicolumn{7}{|c|}{ No. of months before/after OD } \\
\hline Before -72 & $-1.067(0.24 I)$ & $-1.06(0.222)$ & $-1.098(0.257)$ & $-0.991(0.264)$ & $-0.967(0.258)$ & $-0.824(0.289)$ \\
\hline-72 to -61 & $-1.114(0.171)$ & $-1.089(0.18)$ & $-1.057(0.299)$ & $-1.008(0.357)$ & $-0.929(0.209)$ & $-0.714(0.213)$ \\
\hline-60 to -49 & $-0.832(0.154)$ & $-0.756(0.175)$ & $-0.722(0.213)$ & $-0.792(0.252)$ & $-0.88 \mathrm{I}(0.18 \mathrm{I})$ & $-0.821(0.198)$ \\
\hline-48 to -37 & $-0.784(0.148)$ & $-0.673(0.168)$ & $-0.992(0.171)$ & $-0.93(0.203)$ & $-0.842(0.182)$ & $-0.717(0.197)$ \\
\hline-36 to -31 & $-0.99(0.157)$ & $-0.937(0.178)$ & $-1.058(0.254)$ & $-0.99 \mid(0.3)$ & $-0.688(0.174)$ & $-0.648(0.188)$ \\
\hline-30 to -25 & $-0.771(0.135)$ & $-0.725(0.15)$ & $-0.662(0.211)$ & $-0.848(0.267)$ & $-0.702(0.155)$ & $-0.616(0.165)$ \\
\hline-24 to -19 & $-0.73(0.132)$ & $-0.709(0.149)$ & $-0.784(0.188)$ & $-0.763(0.223)$ & $-0.44(0.14)$ & $-0.347(0.149)$ \\
\hline-18 to -13 & $-0.731(0.115)$ & $-0.674(0.127)$ & $-0.769(0.183)$ & $-0.71 \mathrm{I}(0.2 \mathrm{II})$ & $-0.376(0.128)$ & $-0.324(0.139)$ \\
\hline-12 to -7 & $-0.422(0.123)$ & $-0.36 \mathrm{I}(0.137)$ & $-0.429(0.148)$ & $-0.323(0.165)$ & $-0.231(0.118)$ & $-0.196(0.129)$ \\
\hline-6 to -1 & (Reference) & (Reference) & (Reference) & (Reference) & (Reference) & (Reference) \\
\hline I to 6 & $0.557(0.1 \mathrm{I})$ & $0.561(0.119)$ & $0.803(0.1 \mid 4)$ & $0.784(0.131)$ & $0.08(0.104)$ & 0.091 (0.1I4) \\
\hline 7 to 12 & $-0.32(0.097)$ & $-0.252(0.098)$ & $-0.172(0.125)$ & $-0.162(0.134)$ & $-0.323(0.11)$ & $-0.278(0.119)$ \\
\hline 13 to 18 & $-0.404(0.122)$ & $-0.326(0.124)$ & $-0.426(0.16)$ & $-0.404(0.169)$ & $-0.392(0.131)$ & $-0.354(0.142)$ \\
\hline 19 to 24 & $-0.467(0.123)$ & $-0.395(0.128)$ & $-0.303(0.173)$ & $-0.285(0.184)$ & $-0.435(0.149)$ & $-0.399(0.159)$ \\
\hline 25 to 30 & $-0.475(0.143)$ & $-0.416(0.142)$ & $-0.318(0.182)$ & $-0.308(0.187)$ & $-0.139(0.174)$ & $-0.105(0.183)$ \\
\hline 31 to 36 & $-0.414(0.162)$ & $-0.339(0.166)$ & $-0.235(0.2)$ & $-0.229(0.207)$ & $-0.2(0.217)$ & $-0.165(0.227)$ \\
\hline 37 to 48 & $-0.612(0.152)$ & $-0.548(0.155)$ & $-0.64(0.209)$ & $-0.636(0.22 \mathrm{I})$ & $-0.32(0.263)$ & $-0.288(0.27 I)$ \\
\hline 49 to 60 & $-0.422(0.193)$ & $-0.372(0.192)$ & $-0.382(0.23)$ & $-0.38(0.243)$ & $-0.623(0.269)$ & $-0.595(0.28)$ \\
\hline After 60 & $-0.535(0.173)$ & $-0.502(0.175)$ & $-0.678(0.222)$ & $-0.684(0.234)$ & $-0.549(0.242)$ & $-0.535(0.258)$ \\
\hline \multicolumn{7}{|l|}{ Gender } \\
\hline Male & (Reference) & (Reference) & (Reference) & (Reference) & (Reference) & (Reference) \\
\hline Female & $0.142(0.085)$ & $0.114(0.088)$ & $0.057(0.09)$ & $0.07 I(0.10 I)$ & $0.034(0.104)$ & $0.04 I(0.11)$ \\
\hline \multicolumn{7}{|c|}{ Patient age at OD, years } \\
\hline $18-35$ & (Reference) & (Reference) & (Reference) & (Reference) & (Reference) & (Reference) \\
\hline $36-55$ & $-0.192(0.128)$ & $-0.212(0.128)$ & $-0.239(0.176)$ & $-0.324(0.183)$ & $-0.374(0.129)$ & $-0.383(0.133)$ \\
\hline $56-70$ & $-0.152(0.152)$ & $-0.133(0.157)$ & $-0.163(0.206)$ & $-0.225(0.221)$ & $-1.049(0.182)$ & $-1.054(0.191)$ \\
\hline$>70$ & $-0.147(0.164)$ & $-0.117(0.167)$ & $-0.138(0.206)$ & $-0.205(0.217)$ & $-1.03(0.235)$ & $-1.039(0.251)$ \\
\hline \multicolumn{7}{|l|}{ Insurance type } \\
\hline Medicaid & (Reference) & (Reference) & (Reference) & (Reference) & (Reference) & (Reference) \\
\hline Medicare & $0.597(0.161)$ & $0.658(0.165)$ & $-0.008(0.195)$ & $0.044(0.205)$ & $-0.66 \mathrm{I}(0.234)$ & $-0.622(0.243)$ \\
\hline Commercial & $0.734(0.135)$ & $0.767(0.136)$ & $0.099(0.18 \mathrm{I})$ & $0.148(0.193)$ & $-0.642(0.137)$ & $-0.6 \mathrm{I}(0.14)$ \\
\hline \multicolumn{7}{|c|}{ Chronic condition } \\
\hline CKD & $0.259(0.124)$ & $0.198(0.137)$ & $0.437(0.119)$ & $0.462(0.139)$ & $0.235(0.155)$ & $0.266(0.175)$ \\
\hline Diabetes & $0.304(0.091)$ & $0.32(0.096)$ & $0.266(0.112)$ & $0.288(0.124)$ & $-0.082(0.134)$ & $-0.109(0.143)$ \\
\hline Asthma & $0.287(0.109)$ & $0.357(0.113)$ & $0.258(0.127)$ & $0.294(0.138)$ & $0.413(0.115)$ & $0.434(0.12)$ \\
\hline $\mathrm{CHF}$ & $0.553(0.152)$ & $0.527(0.172)$ & $0.473(0.108)$ & $0.421(0.127)$ & $0.213(0.176)$ & $0.192(0.204)$ \\
\hline COPD & $0.368(0.11 \mathrm{I})$ & $0.242(0.096)$ & $0.346(0.104)$ & $0.325(0.118)$ & $0.219(0.115)$ & $0.193(0.124)$ \\
\hline CAD & $0.261(0.087)$ & $0.321(0.091)$ & $0.404(0.107)$ & $0.503(0.115)$ & $0.518(0.112)$ & $0.556(0.115)$ \\
\hline Hypertension & $0.307(0.086)$ & $0.24 I(0.084)$ & $0.192(0.099)$ & $0.166(0.104)$ & $0.129(0.125)$ & $0.109(0.132)$ \\
\hline Cancer & $1.027(0.102)$ & $1.005(0.116)$ & $0.718(0.129)$ & $0.758(0.149)$ & $0.266(0.174)$ & $0.24(0.20 I)$ \\
\hline Depression & $0.577(0.079)$ & $0.586(0.08 \mathrm{I})$ & $0.519(0.085)$ & $0.542(0.09)$ & $0.815(0.087)$ & $0.82(0.09)$ \\
\hline \multicolumn{7}{|l|}{ Year } \\
\hline 2006 & (Reference) & (Reference) & (Reference) & (Reference) & (Reference) & (Reference) \\
\hline 2007 & $0.17(0.134)$ & $0.229(0.138)$ & $0.162(0.17)$ & $0.212(0.194)$ & $0.268(0.16)$ & $0.287(0.169)$ \\
\hline 2008 & $0.403(0.135)$ & $0.448(0.148)$ & $0.489(0.143)$ & $0.579(0.166)$ & $0.197(0.15)$ & $0.186(0.157)$ \\
\hline 2009 & $0.426(0.133)$ & $0.473(0.15)$ & $0.344(0.168)$ & $0.396(0.201)$ & $0.307(0.138)$ & $0.312(0.143)$ \\
\hline 2010 & $0.344(0.135)$ & $0.41(0.148)$ & $0.217(0.173)$ & $0.314(0.207)$ & $0.244(0.178)$ & $0.214(0.191)$ \\
\hline 2011 & $0.134(0.157)$ & $0.192(0.174)$ & $-0.124(0.188)$ & $-0.03(0.222)$ & $0.117(0.161)$ & $0.115(0.17)$ \\
\hline
\end{tabular}


Table SI (Continued)

\begin{tabular}{|c|c|c|c|c|c|c|}
\hline \multirow[t]{2}{*}{ Covariate } & \multicolumn{2}{|c|}{$\begin{array}{l}\text { Total medical cost } \\
\text { (coefficient, SE) }\end{array}$} & \multicolumn{2}{|c|}{$\begin{array}{l}\text { Acute inpatient admission } \\
\text { (coefficient, SE) }\end{array}$} & \multicolumn{2}{|c|}{ ED visit (coefficient, SE) } \\
\hline & All & Exclude deceased & All & Exclude deceased & All & Exclude deceased \\
\hline 2012 & $0.12(0.176)$ & $0.242(0.194)$ & $-0.168(0.182)$ & $-0.045(0.219)$ & $-0.122(0.174)$ & $-0.091(0.183)$ \\
\hline 2013 & $-0.023(0.17)$ & $0.026(0.187)$ & $-0.433(0.2)$ & $-0.374(0.242)$ & $-0.196(0.169)$ & $-0.191(0.178)$ \\
\hline 2014 & $-0.022(0.175)$ & $0.102(0.19)$ & $-0.314(0.2)$ & $-0.214(0.24 I)$ & $-0.119(0.175)$ & $-0.092(0.183)$ \\
\hline 2015 & $-0.27(0.183)$ & $-0.14(0.197)$ & $-0.557(0.215)$ & $-0.439(0.252)$ & $-0.294(0.192)$ & $-0.256(0.199)$ \\
\hline Constant & $6.058(0.21 \mathrm{I})$ & $5.888(0.226)$ & $-3.458(0.254)$ & $-3.617(0.288)$ & $-1.62(0.185)$ & $-1.697(0.196)$ \\
\hline No. of patients & 942 & 876 & 942 & 876 & 942 & 876 \\
\hline No. of member-months & 39,017 & 36,175 & 39,017 & 36,175 & 39,017 & 36,175 \\
\hline
\end{tabular}

Abbreviations: SE, standard error; ED, emergency department; OD, overdose; CKD, chronic kidney disease; CHF, congestive heart failure; COPD, chronic obstructive pulmonary disease; CAD, coronary artery disease.

Table S2 Full regression output for physician office visits

\begin{tabular}{|c|c|c|c|c|}
\hline \multirow[t]{2}{*}{ Covariate } & \multicolumn{2}{|c|}{ PCP visit (coefficient, SE) } & \multicolumn{2}{|c|}{ Specialist visit (coefficient, SE) } \\
\hline & All & Exclude deceased & All & Exclude deceased \\
\hline \multicolumn{5}{|c|}{ No. of months before/after OD } \\
\hline Before -72 & $-0.259(0.109)$ & $-0.248(0.124)$ & $-0.922(0.166)$ & $-0.735(0.179)$ \\
\hline-72 to -61 & $-0.25(0.093)$ & $-0.285(0.101)$ & $-0.438(0.139)$ & $-0.29(0.155)$ \\
\hline-60 to -49 & $-0.246(0.064)$ & $-0.298(0.07 I)$ & $-0.4 I I(0.13)$ & $-0.358(0.145)$ \\
\hline-48 to -37 & $-0.322(0.062)$ & $-0.365(0.069)$ & $-0.447(0.093)$ & $-0.415(0.102)$ \\
\hline-36 to -31 & $-0.202(0.065)$ & $-0.197(0.072)$ & $-0.39(0.096)$ & $-0.34(0.101)$ \\
\hline-30 to -25 & $-0.273(0.06)$ & $-0.332(0.068)$ & $-0.4(0.099)$ & $-0.384(0.103)$ \\
\hline-24 to -19 & $-0.185(0.058)$ & $-0.204(0.064)$ & $-0.265(0.089)$ & $-0.251(0.092)$ \\
\hline-18 to -13 & $-0.192(0.055)$ & $-0.21(0.061)$ & $-0.38 \mathrm{I}(0.072)$ & $-0.36(0.078)$ \\
\hline-12 to -7 & $-0.191(0.049)$ & $-0.211(0.053)$ & $-0.243(0.062)$ & $-0.22(0.069)$ \\
\hline-6 to -1 & (Reference) & (Reference) & (Reference) & (Reference) \\
\hline I to 6 & $0.036(0.047)$ & $0.031(0.05)$ & $-0.019(0.064)$ & $0.037(0.068)$ \\
\hline 7 to 12 & $-0.161(0.054)$ & $-0.163(0.055)$ & $-0.206(0.07 I)$ & $-0.137(0.073)$ \\
\hline 13 to 18 & $-0.162(0.057)$ & $-0.17(0.059)$ & $-0.224(0.08 \mathrm{I})$ & $-0.155(0.082)$ \\
\hline 19 to 24 & $-0.186(0.06)$ & $-0.193(0.06 I)$ & $-0.196(0.083)$ & $-0.128(0.084)$ \\
\hline 25 to 30 & $-0.25(0.067)$ & $-0.257(0.069)$ & $-0.151(0.09)$ & $-0.085(0.091)$ \\
\hline 31 to 36 & $-0.185(0.075)$ & $-0.191(0.076)$ & $-0.385(0.104)$ & $-0.317(0.106)$ \\
\hline 37 to 48 & $-0.187(0.075)$ & $-0.192(0.077)$ & $-0.378(0.098)$ & $-0.312(0.1)$ \\
\hline 49 to 60 & $-0.25(0.088)$ & $-0.255(0.09)$ & $-0.283(0.128)$ & $-0.217(0.13)$ \\
\hline After 60 & $-0.325(0.1 \mathrm{II})$ & $-0.329(0.113)$ & $-0.272(0.146)$ & $-0.215(0.148)$ \\
\hline \multicolumn{5}{|l|}{ Gender } \\
\hline Male & (Reference) & (Reference) & (Reference) & (Reference) \\
\hline Female & $0.094(0.049)$ & $0.083(0.052)$ & $0.182(0.07)$ & $0.24(0.076)$ \\
\hline \multicolumn{5}{|c|}{ Patient age at $O D$, years } \\
\hline $18-35$ & (Reference) & (Reference) & (Reference) & (Reference) \\
\hline $36-55$ & $0.101(0.069)$ & $0.092(0.07 I)$ & $0.072(0.099)$ & $0.048(0.101)$ \\
\hline $56-70$ & $0.075(0.087)$ & $0.07(0.092)$ & $0.185(0.127)$ & $0.136(0.133)$ \\
\hline$>70$ & $0.063(0.099)$ & $0.042(0.105)$ & $0.062(0.143)$ & $0.042(0.15)$ \\
\hline \multicolumn{5}{|l|}{ Insurance type } \\
\hline Medicaid & (Reference) & (Reference) & (Reference) & (Reference) \\
\hline Medicare & $-0.052(0.097)$ & $-0.039(0.1)$ & $-0.28(0.121)$ & $-0.224(0.125)$ \\
\hline Commercial & $-0.22(0.078)$ & $-0.218(0.08)$ & $-0.073(0.101)$ & $-0.04(0.104)$ \\
\hline \multicolumn{5}{|c|}{ Chronic condition } \\
\hline CKD & $-0.031(0.062)$ & $-0.028(0.067)$ & $0.235(0.089)$ & $0.199(0.099)$ \\
\hline Diabetes & $0.16(0.051)$ & $0.18(0.055)$ & $0.19(0.072)$ & $0.194(0.078)$ \\
\hline Asthma & $0.208(0.054)$ & $0.22(0.055)$ & $0.264(0.07)$ & $0.282(0.073)$ \\
\hline $\mathrm{CHF}$ & $-0.005(0.058)$ & $-0.009(0.066)$ & $0.272(0.085)$ & $0.238(0.094)$ \\
\hline COPD & $0.175(0.062)$ & $0.167(0.068)$ & $0.019(0.087)$ & $-0.012(0.092)$ \\
\hline
\end{tabular}


Table S2 (Continued)

\begin{tabular}{|c|c|c|c|c|}
\hline \multirow[t]{2}{*}{ Covariate } & \multicolumn{2}{|c|}{ PCP visit (coefficient, SE) } & \multicolumn{2}{|c|}{ Specialist visit (coefficient, SE) } \\
\hline & All & Exclude deceased & All & Exclude deceased \\
\hline CAD & $0.081(0.05)$ & $0.063(0.052)$ & $0.208(0.069)$ & $0.21(0.074)$ \\
\hline HTN & $0.242(0.049)$ & $0.251(0.052)$ & $0.291(0.078)$ & $0.296(0.082)$ \\
\hline Cancer & $-0.049(0.066)$ & $-0.07(0.068)$ & $0.91(0.078)$ & $0.853(0.091)$ \\
\hline Depression & $0.281(0.046)$ & $0.291(0.048)$ & $0.228(0.067)$ & $0.267(0.07 I)$ \\
\hline \multicolumn{5}{|l|}{ Year } \\
\hline 2006 & (Reference) & (Reference) & (Reference) & (Reference) \\
\hline 2007 & $0.043(0.05 \mathrm{I})$ & $0.08 \mathrm{I}(0.055)$ & $0.063(0.072)$ & $0.038(0.07 \mathrm{I})$ \\
\hline 2008 & $0.117(0.055)$ & $0.109(0.061)$ & $0.084(0.085)$ & $0.072(0.092)$ \\
\hline 2009 & $0.107(0.06 \mathrm{I})$ & $0.112(0.065)$ & $0.049(0.091)$ & $0.079(0.1)$ \\
\hline 2010 & $0.098(0.067)$ & $0.102(0.073)$ & $0.058(0.102)$ & $0.076(0.11)$ \\
\hline 2011 & $0.049(0.067)$ & $0.031(0.074)$ & $-0.052(0.103)$ & $-0.033(0.111)$ \\
\hline 2012 & $-0.026(0.07 I)$ & $-0.008(0.076)$ & $-0.153(0.106)$ & $-0.09(0.116)$ \\
\hline 2013 & $-0.084(0.077)$ & $-0.095(0.082)$ & $-0.297(0.12)$ & $-0.28(0.129)$ \\
\hline 2014 & $-0.087(0.079)$ & $-0.088(0.084)$ & $-0.179(0.125)$ & $-0.131(0.136)$ \\
\hline 2015 & $-0.157(0.087)$ & $-0.161(0.091)$ & $-0.28(0.131)$ & $-0.244(0.14 I)$ \\
\hline Constant & $-1.191(0.101)$ & $-1.183(0.108)$ & $-1.34 \mid(0.152)$ & $-1.489(0.161)$ \\
\hline No. of patients & 942 & 876 & 942 & 876 \\
\hline No. of member-months & 39,017 & 36,175 & 39,017 & 36,175 \\
\hline
\end{tabular}

Abbreviations: PCP, primary care provider; SE, standard error; OD, overdose; CKD, chronic kidney disease; CHF, congestive heart failure; COPD, chronic obstructive pulmonary disease; CAD, coronary artery disease; HTN, hypertension.

Substance Abuse and Rehabilitation is an international, peer-reviewed, open access journal publishing original research, case reports, editorials, reviews and commentaries on all areas of addiction and substance abuse and options for treatment and rehabilitation. The manuscript management system is completely online and includes a very quick and fair peer-review system. Visit http://www.dovepress.com/testimonials.php to read real quotes from published authors. 